\title{
Patients' lived experiences with antineoplastic medicines for the management of malignant solid tumours: a systematic review.
}

BRINCAT, A., BONANNO, P.V., STEWART, D. and WEIDMANN, A.E. 


\section{Accepted Manuscript}

Patients' lived experiences with antineoplastic medicines for the management of

malignant solid tumours: A systematic review

Alison Brincat, Patricia Vella Bonanno, Derek Stewart, Anita E. Weidmann

PII: S1551-7411(19)30073-7

DOI: $\quad$ https://doi.org/10.1016/j.sapharm.2019.06.020

Reference: RSAP 1312

To appear in: Research in Social \& Administrative Pharmacy

Received Date: 31 January 2019

Revised Date: 23 June 2019

Accepted Date: 29 June 2019

Please cite this article as: Brincat A, Bonanno PV, Stewart D, Weidmann AE, Patients' lived experiences with antineoplastic medicines for the management of malignant solid tumours: A systematic review, Research in Social \& Administrative Pharmacy (2019), doi: https://doi.org/10.1016/ j.sapharm.2019.06.020.

This is a PDF file of an unedited manuscript that has been accepted for publication. As a service to our customers we are providing this early version of the manuscript. The manuscript will undergo copyediting, typesetting, and review of the resulting proof before it is published in its final form. Please note that during the production process errors may be discovered which could affect the content, and all legal disclaimers that apply to the journal pertain. 
Patients' lived experiences with antineoplastic medicines for the management of malignant solid tumours: a systematic review

Alison Brincat ${ }^{\mathrm{a}}$, Patricia Vella Bonanno ${ }^{\mathrm{b}}$, Derek Stewart ${ }^{\mathrm{c}}$, Anita E Weidmann ${ }^{\mathrm{a}}$

${ }^{a}$ School of Pharmacy and Life Sciences, Robert Gordon University, Aberdeen, Scotland

${ }^{\mathrm{b}}$ Strathclyde Institute of Pharmacy and Biomedical Sciences, University of Strathclyde, Glasgow, Scotland

${ }^{c}$ Qatar University Health and College of Pharmacy, Qatar University, Doha, Qatar

Corresponding author

Alison Brincat

e-mail: a.brincat@rgu.ac.uk

telephone: 0035679933433

address: School of Pharmacy and Life Sciences, Robert Gordon University, The Sir Ian Wood Building, Garthdee Road, Aberdeen, AB10 7GJ, Scotland

E-mail addresses of authors:

Patricia Vella Bonanno: patricia.vella-bonanno@strath.ac.uk

Derek Stewart: d.stewart@qu.edu.qa

Anita E Weidmann: a.e.weidmann@rgu.ac.uk

Declarations of interest: none 
Patients' lived experiences with antineoplastic medicines for the management of malignant solid tumours: a systematic review

\begin{abstract}
Background: Antineoplastic medicines affect the patients' physical and psychosocial well-being posing challenges for patients, caregivers and healthcare professionals. However, little is known about the patients' lived experience with medicines (PLEM) for antineoplastic treatment. It is the lived experience that gives meaning to each individual's perception of a particular phenomenon which is influenced by internal and external factors relevant to the individual.
\end{abstract}

Objectives: To critically appraise, synthesise and present the available evidence of patients' lived experience with antineoplastic medicines prescribed for the management of malignant solid tumours.

Method: A systematic literature search was conducted in six electronic databases for articles published in English with no date restrictions. The search terms were related to beliefs, practice and burden in relation to patient, antineoplastic medicines, tumours and lived experience. Study selection, quality assessment and data extraction were performed independently by 2 reviewers. Research findings were analysed using narrative and meta-synthesis approaches.

Results: The search retrieved 31,004 articles with only 10 studies satisfying the inclusion and exclusion criteria. These studies were published between 2005 and 2016 in Europe $(n=6)$, America $(n=3)$ and Asia $(n=1)$. Nine themes were identified to contribute to the patients' lived experience with antineoplastic medicines. These were (a) influence from family members, healthcare professionals, media and culture, (b) general attitude towards medicine, (c) accepting medicine, (d) modifying or altering medicine regimen or dose, (e) medicine characteristics, (f) medicine routine, (g) medicine adverse events, (h) medicine and social burden and (i) healthcare associated medicine burden. Patients tend to undergo a continuous process of reinterpretations of their experience with medicines throughout their treatment journey.

Conclusion: The use of antineoplastic medicines has a profound effect on the patients' lives. Further longitudinal in-depth studies are required to provide deeper insight into PLEM and support patients in their treatment journey.

Keywords: solid tumor; antineoplastic medicines; patients' lived experience with medicine; medicine-taking practice; medicine-related beliefs; medicine-related burden

\author{
Abbreviations: \\ PLEM - Patients' Lived Experience with Medicines \\ CASP - Critical Appraisal Skills Programme \\ EPHPP - Effective Public Health Practice Project \\ PRISMA-P - Preferred Reporting Items for Systematic Reviews and Meta-Analyses Protocol \\ PROSPERO - International Prospective Register of Systematic Reviews
}




\section{Introduction}

Cancer is a group of related diseases featured by uncontrolled growth and dissemination of abnormal cells; with more than $80 \%$ of all cancers being solid tumours. ${ }^{1,2}$ Cancers with the highest incidence amongst both genders are solid tumours in the breast, lung, colorectum and prostate. More than 18 million patients were newly diagnosed with cancer worldwide in 2018. ${ }^{3}$ It is being projected that by 2030 the number of newly diagnosed cancer cases will rise to over 22 million per year predicted on the basis of an aging population and adoption of behaviours linked with socio-economic development. Hence it is being considered as an enormous international health burden growing at an alarming pace. ${ }^{2,4,5}$

Antineoplastic medicines, which are often used as part of the treatment in combination with surgery and radiation, interfere with cell growth resulting in apoptosis of cancer cells. Over the years, advances in cancer care have led to prolonged cancer remission and management even when cure cannot be achieved. Hence cancer is being considered as a chronic condition. ${ }^{2,6}$ The number of cancer survivors in America is expected to increase from 15.5 million in 2015 to 20 million by $2026 .^{7}$

Patients, themselves, are primarily responsible for the management of their health. Patient participation within the healthcare systems includes the involvement of the patient in decision making, expressing opinions about different treatment methods such as sharing of information, feelings and cooperating with the healthcare professionals' advice. The concept of enabling active patient participation is increasingly noted as a key component in the redesign of healthcare services and also as means to improve patient safety. ${ }^{8,9}$

The medicine experience incorporates the patient's description of his expectations, concerns, beliefs, cultural, ethical and religious influences on medicine-taking behaviour. Cipolle et al. (2004) developed the concept of medicine experience defined as "the sum of all the events a patient has in his/her lifetime that involves drug therapy." This approach is emphasised in the practice of pharmaceutical care as it focuses on patient-centred approach by providing direct care to patients based on their medicine-related needs. ${ }^{10}$ Similarly, Shoemaker and Ramalho de Oliveira in 2008 defined "the medication experience as an individual's subjective experience of taking a medication in his daily life." ${ }^{11}$ The concept of lived experience stresses the fact that only those who have experienced the phenomena can communicate their real experience to the outside world. ${ }^{12,13}$ A conceptual model of patients' lived experience with medicines was compiled in a metasynthesis of qualitative studies by Mohammed et al. (2016). As depicted in Figure 1, this incorporated medicine-related burden, medicine-related beliefs and medicine-taking practice. These concepts will in turn affect the patients' wellbeing and health-related quality of life together with therapeutic outcomes. ${ }^{14}$

Healthcare professionals' behaviours, family members and peers influence the patient's beliefs towards medicines. The intensity of medicine-related burden and the coping skills of the individual influence the patient's attitude and behaviour to the use of medicines. Positive attitudes arise from trust in healthcare professionals, positive medicine experience and achievement of the desired therapeutic outcomes. The medicine-related beliefs with the effect of the medicine-related burden influence the medicine-taking practice. ${ }^{14,15}$ Medicine-related burden incorporates the medicine regimen, characteristics, adverse events together with the social and healthcare effects. Mohammed et al. (2016) showed that intolerable medicine burden often resulted in non-adherence and poor treatment outcomes. ${ }^{14}$ In addition, a study on 97 Australian participants identified medicine-related burden as one of 4 interrelated components of treatment burden (financial, time, travel and healthcare access burden) operating in a cyclical manner. ${ }^{16}$

The focus of cancer care is centred on improving patient experience by understanding the burden they meet in everyday life, as well as the unmet needs of treatment such as treatment adverse effects and quality of life. These insights can be achieved through direct and constructive interactions with patients. ${ }^{9,17}$ 
The increasing number of publications including systematic reviews in the field of oncology indicates that the care of cancer patients persists as a clinical research priority. The majority of the systematic reviews evaluated cancer drug treatment effectiveness, safety and supportive care interventions. ${ }^{18}$ Despite this, systematic reviews about medicine experiences of adult cancer patients undergoing antineoplastic treatment are lacking. The aim of this systematic review was to critically appraise, synthesise and present the available evidence of patients' lived experiences of antineoplastic medicines prescribed for the management of malignant solid tumours.

\section{Method \\ Protocol registration}

A systematic review protocol was developed in accordance with the Preferred Reporting Items for Systematic Reviews and Meta-Analyses Protocol (PRISMA-P) standards. ${ }^{19}$ The protocol was then registered with International Prospective Register of Systematic Reviews (PROSPERO) [PROSPERO2016:CRD42016048457] to avoid unplanned duplication of work. ${ }^{20}$

\section{Eligibility criteria}

Studies were included in the systematic review if:

- the recruited patients were aged $\geq 18$ years irrespective of their gender, ethnicity and stage of disease and were receiving antineoplastic medicines for the management of malignant solid tumours in any setting; and

- the views, experiences and behaviours of patients in receiving antineoplastic medicines from their perspective were reported; and

- the study incorporated all the 3 aspects of the patients' lived experience with medicines concept: medicine-related beliefs, medicine-related burden and medicine-taking practice as outcome measures.

Studies were excluded if they investigated the patient experience in experimental studies rather than the 'real world' setting, they included experiences of patients taking antineoplastic medicines solely for palliative intent, studies reported in a non-English language or published as conference abstracts and grey literature.

\section{Search strategy}

A database search strategy using specified search terms and their different combinations was created in consultation with the research team. The key concepts of the patients' lived experience with medicines, extracted from the model developed by Mohammed et al. (2016), were medicine-related burden, medicine related-beliefs and medicine-taking practice. The search focused on these concepts in relation to patient, antineoplastic medicines, malignant solid tumours and lived experience. Concept mapping was utilised as an aid to consider all aspects of the topic and identify keywords that may be used for the search. The search strategy was then adapted to meet the specifications of the different databases.

A systematic literature search was conducted in six databases: Cumulative Index to Nursing and Allied Health Literature (CINAHL), Medline, Cochrane Database of Systematic Reviews, Embase, International Pharmaceutical Abstracts and PsycArticles. The manual search of related studies in the references of identified publications was carried out to identify additional potentially relevant papers.

\section{Study Review}

Screening was performed first on titles, then on abstracts and then followed by full papers in accordance to the inclusion and exclusion criteria. A random sample of $10 \%$ of the retrieved titles and abstracts and the whole list of full papers were screened independently by 2 members of the research team for 
consistency of inclusion/exclusion and to enhance the reliability of the process. Any disagreement was resolved following discussion and consensus was reached within the research team.

\section{Quality assessment}

Studies were appraised using quality appraisal forms adapted from the Critical appraisal skills programme $(\mathrm{CASP})^{21}$ and Equator Network ${ }^{22}$ for qualitative research together with the quality assessment tool of the Effective public health practice project (EPHPP) for quantitative research. ${ }^{23}$ Quality assessment was performed independently by 2 reviewers. Any disagreements were discussed and resolved by consensus.

\section{Data extraction and synthesis of results}

Data extracted from the articles included specific details about the populations, study setting, research design, method, salient findings and study limitations. The research findings of the quantitative and qualitative studies were analysed using narrative and meta-synthesis approaches respectively. This systematic review implemented the qualitative meta-interpretative synthesis (QIMS) methodology for qualitative studies in an attempt to "create a new, deeper, and broader understanding" of the phenomenon. ${ }^{24}$ QIMS allows the extracted data to be analysed through a process of coding, theme extraction, theme synthesis and triangulation. ${ }^{25,26}$ After repeatedly reading the included studies, sections identified to fall within one of the 3 main categories: (1) medicine-related beliefs, (2) medicine-taking practice and (3) medicine-related burden in accordance to the model of Mohammed et al. (2016) were extracted and reported verbatim in line with the corresponding theme. The quotes, if available, were pulled directly from the study. This was independently done by the first researcher and another researcher within the team to ensure that all extracts within the study were identified and grouped in the same category. Then the studies were translated into each other. Proposed themes and sub-themes were put forward by all researchers through an iterative process. The theme synthesis process utilises triangulation to enhance dependability and trustworthiness of the findings. Triangulation is based on 4 processes, namely methods, sources, analysts and theoretical perspectives. ${ }^{24,25}$

\section{Bias}

The risk of bias was minimised by the application of the following measures:

- A random sample of $10 \%$ of studies identified during the database search was independently assessed for relevance by two independent reviewers.

- Quality assessment using standardised critical appraisal instruments and data extraction of all selected papers was conducted by two independent reviewers prior to inclusion in the review.

- Disagreements were resolved by consensus after discussion with the research team.

\section{Results Study selection}

As shown in the Prisma flow diagram ${ }^{27}$ (Figure 2), the combined search yielded 31,004 titles. A total of 10 studies met the inclusion criteria and were included in the systematic review. ${ }^{28-37}$ Two studies were quantitative studies and 8 studies followed qualitative methodology.

\section{Description of the selected studies}

The characteristics of the included studies are summarised in Table 1. Studies were published between 2005 and 2016 and were conducted on 3 continents: Europe $(n=6)$, America $(n=3)$ and Asia (n=1). Sample sizes ranged from 1 to 92 participants. Qualitative studies were conducted on 153 patients in total whilst quantitative studies investigated 154 patients. Four studies included solely male participants whilst only 1 study involved only female participants in the sample population. Six studies investigated patients 
suffering from a single cancer type: advanced non-small cell lung cancer ( 2 studies), breast cancer (3 studies) and colorectal cancer (1 study). The remaining 4 studies did not focus on any particular cancer type but involved patients suffering from various solid tumours. The treatment strategy varied across all 10 studies. Two studies focused on patients receiving capecitabine, two studies included patients receiving erlotinib or completed adjuvant antineoplastic treatment (fluorouracil, epirubicin and cyclophosphamide treatment protocol) respectively and the other six studies involved patients receiving different antineoplastic treatment protocols.

The majority of studies $(n=8)$ used a range of qualitative methods which included focus groups ( 1 study), open interviews ( 2 studies), semi-structured interviews (2 studies) or multi-method approach consisting of observational study with semi-structured interviews with or without the use of field diary (3 studies). Two further studies used a quantitative approach where data was collected using patient-reported questionnaires, blood sampling and patient's medical files.

Out of the 10 studies, 3 studies did not state at which point in the patient's cancer journey the interview was conducted. Six studies collected data during the patient's treatment phase whilst 1 study took a retrospective look at patients who had completed chemotherapy within the previous year. Qualitative data of included studies were analysed using content analysis, grounded theory and ethnography. Hence this systematic review satisfied the 4 triangulation processes.

\section{Quality assessment of the included studies}

The quality assessment of the included studies is summarised in Appendices 1-4. The strengths of the studies included a clear research aim in $80 \%(n=8)$ of the studies, an appropriate study design and the attainment of ethical approval in all the studies except one where it was unclear whether ethical approval was granted. The results obtained in the majority of the studies $(n=8)$ clearly addressed the original research question and the key findings were explained in detail.

The weaknesses of the selected studies included the lack of justification for the final sample size in the manuscript $(n=2)$ and the lack of discussion on the limitations of findings such as triangulation, bias and confounders $(n=8)$. The latter clarifies the extent to which the findings offer an accurate representation of the phenomenon under study, hence affecting the validity and reliability of research findings.

\section{Data synthesis}

The studies included in this systematic review did not provide a standard definition of the patients' lived experience with medicine. Nine themes emerged to highlight the patients' lived experience with antineoplastic medicines in patients suffering from solid tumours: medicine-related beliefs (two themes), medicine-taking practice (two themes) and medicine-related burden (five themes). The themes and subthemes generated from this systematic review were mapped and presented in line with the structure of the PLEM model (Figure 3) adapted from the conceptual model of Mohammed et al. (2016). Modifications in the adapted model included the elimination of medicine related burden, magnitude and coping skills from the main theme of medicine-related beliefs and the inclusion of the sub-themes within the model to ensure a clear understanding.

\section{Medicine-related beliefs}

The identified themes within medicine-related beliefs included (a) influence of healthcare professionals, family members, media and culture as well as (b) general attitude towards medicine.

(a) Influence of family members, healthcare professionals, media and culture 
Chemotherapy, as a treatment, was found to be unique in being considered "as the source of suffering" both culturally and medically. ${ }^{31}$ Suffering encompassed both a meaning and a value for each cancer patient. The myths and stigma associated with cancer treatment may have silencing effects and may influence the patient's behaviour resulting in patients seeking support at a later stage of treatment. ${ }^{28,31}$

Patients tend to follow the healthcare professionals' treatment recommendation to base their decision on whether to initiate treatment or not. The trust of the patient in the healthcare professionals' attitudes and their relationship act as a driving force in their treatment decision and has a strong positive influence on compliance with the medicine. ${ }^{28,33}$ "I don't know if I'm that brave yet, but if my doctors assured me this was a good move, this was a good move for me, I feel confident enough in [my doctor] to follow his advice." 33

Family members have also shown to be highly influential on patients' beliefs and this was reflected in the patients' decisions regarding treatment. Patients disclosed their feelings of responsibility towards their family members as they felt obliged to survive even if this was associated with suffering and restrictions. ${ }^{33,35}$

"Yes, I just thought that if something comes back again and I say no, then I have to look my family and friends in the eye and say I could have prevented it, perhaps. Now, if something comes back again, I can say I did everything I could. Cancer is bad enough without someone saying: It's your own fault!!",35

Media and support groups have been found to strongly influence the cancer patient's beliefs. Newly diagnosed cancer patients may even obtain a false picture about cancer and its treatment from these sources and this may provoke unnecessary anxiety. ${ }^{29,}{ }^{31}$ Cultural aspects also affect patients' outlook on cancer and its treatment as different cultures have diverse views on life, death and pain in general. ${ }^{28,31}$

\section{(b) General attitude of the patient towards medicine}

Chemotherapy is considered as one of the current treatment strategies that may lead to a disease-free future and ultimately to survival. ${ }^{28}$ Studies showed that prior to the initiation of treatment patients already had pre-conceived notions and expectations about their treatment. A commonly expressed idea amongst patients is that chemotherapy "hurt the good cells and really hurting the cancer cells." "30,31,35 Several feelings were expressed by patients at initiation of treatment with antineoplastic medicines. These included hope ${ }^{28,33}$, anxiety, stress ${ }^{29,35}$, fear and also acceptance to carry the burden of side effects. ${ }^{35}$ It was noted that although chemotherapy provides grounds for "hope" "33, this is a highly feared form of treatment that is commonly considered to be as bad or worse than the experience of cancer itself. ${ }^{30,31}$ Patients expressed concerns related to aesthetic adverse effects such as hair loss, feeling of sickness and dependency on intake of medicines. "When I found out that I was going to have chemotherapy my whole world came apart. It was the worst thing I could imagine." ${ }^{30}$ As treatment cycles progressed, patients reported to feel calmer and more peaceful (mean value of the mental component of SF-12 Health Survey improved from $47.1 \pm 7.5$ at baseline to $50.4 \pm 5.4$ at cycle 5$){ }^{37}$

When looking to the future, patients pondered if their current chemotherapy would be successful or whether they would require to continue or change treatment. Patients were also concerned about the frequency of follow-up visits with the oncologist, the monitoring of symptoms in relation to the disease and the adverse effects in relation to treatment. ${ }^{28,29}$ Notwithstanding the fact that the negative feelings particularly in relation to the side effects symptoms were still fresh in the patients' minds, patients were worried about their ability to continue with further chemotherapy sessions whilst coping with experience of their previous treatment. ${ }^{29}$ "....But I can't think about if I were to find out that the cancer had spread, (and if I were to need more treatment)_how would I then manage to go through chemotherapy again, now that I know about everything, now that I have all the answers." 29 At the same time however they anticipated the time when their treatment would be completed and were looking forward to a normal life. 
Some patients argued that they perceived their life to have changed forever and were concerned about continuing to live their life without treatment but with a lack of energy and a fear of disease recurrence. "After treatment I want to begin with a trip to the archipelago (islands that lie outside Stockholm) because that is where I get strength, and I come out of there different, if you compare it to when you are in the city or town. I have been so close to death and gone through this treatment-well, it is present all the time..I am going through counselling right now, since I don't want to put my family through the motions all the time.." 29

\section{Medicine-taking practice}

The themes generated in relation to medicine-taking practice were (a) accepting medicine and (b) modifying or altering medicine regimen or dose.

\section{(a) Accepting medicine}

Qualitative studies revealed that upon receiving the news of suffering from the life-threatening condition of cancer, the focus shifted from diagnosis to treatment and survival. ${ }^{35}$ Patients also wanted to know the intent of treatment to be able to decide whether to undergo treatment and live longer; "if this disease has no cure you can tell me, because in this case I do not wish any treatment.... He told me that that depends on the case: if the disease is already too advanced, it is not worth to treat!" 28

Patients claimed to be highly adherent to antineoplastic medicines. ${ }^{32,34,35}$ Quantitative studies in patients receiving erlotinib showed that the mean adherence was $96.8 \% \pm 4.0 .{ }^{34}$ Using the pill count method patients treated with capecitabine showed a high adherence rate with only $8 \%(n=7)$ consuming less than $95 \%$ of treatment whilst one patient was taking "more than $105 \%$ of the prescribed dose." .37

The treatment-free period between treatment cycles was medically prescribed interruption from treatment either in accordance with the treatment protocol or due to adverse effects. Patients associated these breaks as periods of relief and freedom from constraints to the medicine plan such as "holidays" " or as burdensome periods with adverse effects with "fear of recurrence." ${ }^{33}$ This emphasised the importance of involving the patient in treatment decision making and explanation of treatment.

Along the treatment journey, patients were building up their knowledge about the effects of chemotherapy, interpreting the physical reactions experienced and developing coping mechanisms. Hence these patients underwent a continuous process of reinterpreting their situation. ${ }^{28}$ Collectively, patients described the treatment journey in cancer as a "degrading experience and anxiety-provoking" as these patients had to manage various side effects along the treatment phase. A fear of "change" was highly emphasised; this did not only include the physical appearance especially in women but also the loss of the normal routine and their identity as they may be considered as a cancer case. ${ }^{29,30}$ Although patients were learning to accept the illness, they still wanted to maintain control over their body. ${ }^{30}$

\section{(b) Modifying or altering medicine regimen or dose}

Patients, especially those receiving parenteral chemotherapy treatment, expressed their concern regarding dose reduction and postponement of chemotherapy regimen by healthcare professionals. "When the oncologist offered to administer more chemotherapy cycles with a lowered dose, she enquired whether this would still provide the optimal benefit and the oncologist replied "They've lowered lots of people"...She was scared and had enquired with the oncologist whether this will cause the cancer to grow faster." ${ }^{31}$ Self-reported non-adherence measured by MARS showed increasing rates of modifications in treatment over time ranging from $16 \%(\mathrm{n}=12)$ at cycle 1 to $29 \%(\mathrm{n}=16)$ at cycle $5 .{ }^{37}$ Qualitative comments noted that cancer patients receiving oral antineoplastic medicines may self-alter their prescribed treatment regimen resulting in either under or over dosing of the treatment. The underdosing 
phenomenon may occur by unintentionally missing or deliberately skipping a dose to reduce the severity of unbearable adverse effects such as gastrointestinal symptoms. On the other hand, overdosing may occur when some patients claimed to consume the remaining forgotten medicines at the end of the cycle and a patient even admitted that "he did not always respect the break in-between cycles.",32,34,37 Delays in chemotherapy schedule and dosage reduction have instilled fears in making the tumour "grow faster" and promote recurrence. Most people receiving cytotoxic chemotherapy seek to obtain certainty over uncertainty. The importance of taking treatment exactly as prescribed and receiving "100\% dose" was emphasised by the majority of patients. ${ }^{31,32}$

\section{Medicine-related burden}

Five themes emerged for medicine related burden, these were (a) medicine characteristics (b) medicine routine (c) medicine adverse events (d) medicine and social burden (e) healthcare associated medicine burden.

\section{(a) Medication characteristics}

The patients' experience in relation to medicine characteristics was adversely influenced by the dosage form of treatment, ${ }^{31}$ colour of the parenteral infusion bag ${ }^{29}$ and tablet size. ${ }^{35}$ Patients recalled their physical revulsion to the intake of oral antineoplastic formulation due to the size and form of the tablets that may be too difficult to swallow, profound throat discomfort and the metallic after-taste. ${ }^{35}$

Patients remarked that watching the nurse wearing the personal protective wear and following the procedure to initiate the parenteral infusion created an appalling experience to the patient. This made them recall that ultimately they would be experiencing adverse effects from such treatment. A patient metaphorised his feeling as being "chained" to the infusion line. "Especially the moment when the nurse entered the room wearing protective gear and started the infusion, to be hooked up and to see the chemotherapy infuse the blood vessel, and to know that this also will give some side effects was a terrifying experience." 29

\section{(b) Medicine routine}

In the qualitative studies, medicine routine burden considered aspects that related to the identification of challenges in adapting to the incorporation of antineoplastic treatment into the patient's lifestyle and strategies to overcome these challenges. Patients made great effort to adhere to the prescribed doses and schedules of chemotherapy due to the continuous awareness of the life-threatening nature of the illness metaphorised as "pills dominate the mind.",32,35 This attitude was the "only task that was not delegated to others" as they felt that they "invested all their energy" so as to feel "actively engaged in fighting against" cancer. $^{35}$

It appears that patients develop individualised treatment strategies to assist them with the adherence procedure such as counting of tablets, preparing the tablets from the day before, storing the medicinal product in a "clearly visible prominent place" or setting alarm on their mobile phone. More than $70 \%$ of patients stated that they relied on the reminder method to support their treatment regimen. No association was established between adherence as monitored with Medication Event Monitoring System and the practice of the reminder method for erlotinib intake. ${ }^{34}$ The use of the reminder method was noted in more than $60 \%$ of patients receiving capecitabine at cycle $1(61.5 \%, \mathrm{n}=47), 3(66.2 \%, \mathrm{n}=44)$ and $5(73.2 \%$, $\mathrm{n}=41)$. $^{37}$

Despite the patients' determination to precisely adhere to the prescribed medicine plan, patients identified barriers that could interfere with the adherence process. These include uncertainty in taking the correct number of tablets, skipping the exact time for intake, disruption in their daily routine and running out of 
pills. $^{35}$ Thirteen percent of patients $(n=10)$ did not adjust the administration of capecitabine with meal times at cycle 1 , a behaviour that increased by $10.9 \%$ towards cycle $5 .^{37}$ This is comparable with $21 \%$ $(n=8)$ of patients in the study by Timmers et al. (2015) who did not follow the advice of taking erlotinib under fasting conditions at 1 month. Using the generalised estimated equations, the occurrence of ocular symptoms $(p=0.031)$ and stomatitis $(p=0.005)$ were found to be significantly increased with incorrect intake of erlotinib without food. ${ }^{34}$

\section{(c) Medicine adverse events}

Adverse events were considered as one of the most challenging aspects of living with antineoplastic medicines. Patients referred to different adverse effects which ranged from minor to severe lifethreatening effects with the psychological and physical impact of these adverse effects affecting the patients' quality of life. ${ }^{28,30,32,35,36}$ A cognitive decline manifested as lack of concentration, deteriorating memory and dizziness was noted during and after antineoplastic treatment. ${ }^{30,35}$ Few participants reported of suffering from mild cognitive impairment described as "empty head" and "fog" which adversely affected their concentration. ${ }^{36}$ A few patients considered it strange to suffer from symptoms caused by the treatment and not from the actual illness. ${ }^{30}$

The extent and severity of adverse effects due to antineoplastic treatment played a huge role in many patients' attitudes. ${ }^{29,33}$ A female patient expected to feel better with every chemotherapy cycle however she was frustrated when she started feeling side effects again. ${ }^{28}$ All patient-reported symptoms were reported to worsen from baseline to 1 month of treatment with erlotinib (with the exception of headache). Rash, fatigue and cough were the three most common patient-reported symptoms after 2 months. ${ }^{34}$ Thirty three percent of patients blamed side effects for the discontinuation of treatment with capecitabine prior to completion of the $5^{\text {th }}$ cycle. The commonest patient-reported symptoms with capecitabine at cycle 5 were hand and foot syndrome, fatigue and flatulence In view that these patients had already reported the symptoms at baseline, were pre-treated and/or receiving capecitabine concomitantly with oxaliplatin/irinotecan, it is difficult to attribute these adverse effects solely to capecitabine. ${ }^{37}$

The majority of patients were still experiencing side effects after stopping treatment, with effects being cumulative and worsening over time. However, several patients were surprised to experience relatively few side effects during their course of chemotherapy, both for orally and parenterally administered antineoplastic treatment. $^{31}$

The aspect of "suffering" is so ingrained with the experience of chemotherapy that it is not even recognised as an adverse effect of treatment. ${ }^{31}$ Hence patients failed to recognise adverse effects from these medicines and refrained to inform the healthcare professionals about the occurrence and severity of adverse effects they experienced. ${ }^{28,32,35}$ The patient's ability to tolerate the adverse effects is associated with the concept of making an effort to achieve cure or disease control and may be considered as the "price to pay" for treatment efficacy. ${ }^{32}$ Patients face adverse effects differently, they either accept to support their adverse effects and have a fatalist attitude or they resort to complementary medicine such as phototherapy, homeopathy and hypnotism. The focus groups discussions revealed that patients wait between 3 and 8 days prior to consulting medical advice. Some cancer patients even tried to hide or minimise their adverse effects by either not considering them as severe or by preferring not to talk about them. $^{32,35}$ The latter may be the result of feeling afraid that the oncologist would change their treatment and hence reduce the possibility of a positive response. Few patients felt uncomfortable to speak about adverse effects during every appointment or to discuss specific intimate adverse effects such as vaginal dryness. $^{30,32,35}$

\section{(d) Medicine and social burden}


Despite having treatment, patients put all their efforts to be as positive as possible and lead a normal life. They realised the significance of every day and felt determined to appreciate their lives. "30,36 "But because of the experience of illness, I realize how precious each day and normal life is." 30

Antineoplastic medicines affect the patient's social life which is directly related to their quality of life. Patients experienced social isolation often due to altered relationships with family members and friends. $^{29,30,35,36}$ This may be the result of adverse effects, complex treatment regimen or social stigma. As treatment became the focal point of the cancer patients' lives, this also dominated both their social and family life. "I stopped playing with the orchestra in November of last year. That also has something to do with (name of medication); I got shaky and it had a few other side effects than with (intravenous) chemo." 35 Patients described this period as hard to get through and they focused all their efforts on their feelings. "And then there was the constant worry that the lab tests wouldn't be good so that everything would have to be postponed, and my whole life was about this.."30

In contrast, cancer patients recognised the support provided by family members for proper medicines use and the benefits of support groups. ${ }^{29,30,33,35,36}$ The illness was described as a dramatic, traumatic and insane experience for the family. Family members offer paramount support to cancer patients, with the role of the spouse often considered as a "lifeline". ${ }^{30}$ The partners were specifically identified as providing aid in the patients' daily life such as doing the household chores as this allows the patients to rest when they felt tired. ${ }^{35}$ However there were other patients who felt as if their family did not take any extra consideration. The necessities of time and support to the patient from their relatives was usually overlooked, demonstrating the importance that relatives are aware of the patient's requirements. ${ }^{30}$

Patients also spoke about the impact of treatment on the patients' work and financial income bringing about instability in life. "Chemotherapy brings a lot of anxiety, because I don't know if I can accept an order for or not. You know, there is no lack of work, but if you don't deliver as promised the costumers forget about you. It's bad time for work now.... But it'll become better." ${ }^{28}$ Patients, predominantly females, voiced a sense of gratitude for being granted sick leave during their treatment period. This provided time to completely devote their life to themselves. Patients disclosed their difficulties in returning back to their workplace. They described feeling pressured from society and healthcare professionals to return to their workplace as early as possible. The patients' inner worry was that their employer expected to receive the same work output like before their diagnosis. Some women explained that specific work environments, such as working with children, may result in a higher risk of contracting infections. This may have contributed to their decision not to return to work during treatment. Some women narrated that when they spoke about cancer at the work place; this proved to be taken negatively both by employers and work colleagues. "But then I noticed, and when I came back and started to work full-time my boss came to me and said that this position I had applied for had gone to someone else because I had to think of my illness." 30 Those cancer patients who persisted with the working life had noted that work became important part of life and aided them to detach themselves from the illness itself. 28,30

\section{(e) Healthcare associated medicine burden}

Challenges associated with the complexity of the healthcare system were identified. Healthcare professional-patient relationships, ${ }^{29,30}$ patient-patient relationships, ${ }^{29}$ healthcare support ${ }^{29,30}$ and provision of information ${ }^{30}$ were commonly described. Cancer patients looked for professionalism and traits such as empathy, respect and good support from healthcare professionals. The support offered by healthcare professionals was overall rated as positive. ${ }^{29,30}$ "Well the important thing is of course how they care for you, and not that it has to be so incredibly professional so that, that...Empathy is alpha and omega. And I think they are good and I always tell them that when they ask." ${ }^{30}$ Provision of good quality information 
from healthcare professionals delivered at the appropriate time was considered to be important and made a positive effect in the patients' experiences. In fact, patients felt the large amount of information delivered, especially during the meeting when the oncologist broke the news about their diagnosis, as very "stressful". ${ }^{29,30,32}$ Patients described that healthcare professionals should consider each patient to know nothing about the disease and the treatment and fulfil their information needs with plain, correct and clear material. ${ }^{30}$

Cancer patients identified transportation, distance to hospital for multiple visits, hospital waiting time, companionship with caregivers to treatment and financial burden as barriers to treatment. These difficulties decreased the patients' enthusiasm to continue long-term maintenance treatment with antineoplastic maintenance. ${ }^{29,33}$ "I live alone as well, and every time I come for chemo or transfusions I have to have someone bring me. So that would-if I had to come real frequently that would put a hardship on." 33 Patients commented on the lack of tranquil hospital environment and individualised support by hospital staff. Although the patients receiving oral antineoplastic treatment in the comfort of their own home was considered to be a major advantage, they complained of insecurity about not receiving professional counselling and support at home. ${ }^{29,35}$

Some patients felt that other patients may offer companionship and moral support particularly when they accompany one another during treatment cycles. During the chemotherapy outpatient clinic, cancer patients interacted with each other and also served as a network of support. They would transmit to each other positivism, strength and a feeling of unity. ${ }^{28,30}$ "Yes, it is very important to have someone to share this with because other people do not know what you're talking about. You can explain but they do not know what chemotherapy treatment is. ${ }^{30}$ Whilst being an in-patient to receive parenteral treatment, one patient even praised the consideration of healthcare professionals who ensured patients of similar age and treatment share the same hospital room. However others mentioned the negative psychological impact in the announcement that a patient in their group is suffering from a terminal disease which will reasonably result into death within a short period of time. "For the first treatment I was placed in a four-bed room and I remembered that I thought it was so hard, really hard; for one thing, I had just found out my diagnosis.... and then you just see old people and it gets so obvious what am I doing here. You know it was absolute, I didn't want to be there with all the drainage bags they had, and it was hard. But since then it has been so nice because I was able to change rooms and she (another patient) is the same age as me; we do the treatment together and I think it's great that they have scheduled us together and that we can share a room." 29

Patients enquired about the lack of available treatments despite the ongoing research in oncology. ${ }^{31,33} \mathrm{~A}$ cancer patient made reference to fluorouracil, a standard antineoplastic medicine which has been available for the past 20 years and is still in use; hence can be considered as quite an old drug. He considered this as a bad thing in the light that continuous research is being conducted in this field and remarked, "Surely we can do better than that!",31

\section{Discussion}

The systematic review indicates that none of the published papers provided a standard definition of the patients' lived experience with medicine. The systematic review showed that PLEM is a highly subjective and complex concept, with a lot of considerations. Hence this systematic review supports the model which offers a better framework for PLEM. The model developed by Mohammed et al. (2016) is comprehensive and encapsulates the important aspects in PLEM. This systematic review identified lack of studies with none of the identified studies making use of the PLEM model. Despite the inclusion of a small number of studies in this systematic review, this has captured all the themes related to medicinerelated beliefs, medicine-taking practice and medicine-related burden mentioned in the model by Mohammed et al. (2016). Hence, this model is likely to be transferable to the oncology setting with slight modifications. ${ }^{17}$ 
Collectively researchers provided an extensive account on beliefs, practice and burden of patients receiving different antineoplastic medicines. Patients considered this treatment either as hope or worse than the illness itself. This systematic review showed that patients' treatment decision was highly influenced by the healthcare providers' and carers' preferences. Patients should be informed about all treatment options and be part of the treatment decision in order to be recognised as equal partners in the healthcare team. ${ }^{38,39}$

The introduction of oral antineoplastic agents has altered the outlook of provision of cancer treatment from a controlled monitored procedure in hospital for parenteral treatment to individualised responsibility in the patient's home. This created a major shift in the roles of healthcare professionals mostly doctors, nurses and pharmacists onto patients and carers. ${ }^{40}$ Experienced patients who had received different antineoplastic treatments argued that intravenous chemotherapy necessitates an autonomous behaviour solely for managing side effects. On the other hand, the medicine-taking practice together with the monitoring of adverse effects of oral antineoplastic is more dependent on the patient's autonomy. This systematic review showed that patients voiced their concern that information about treatment was given by healthcare professionals at a time when they were not able to fully comprehend and pose the necessary questions. Hence patients expressed their need of treatment-specific education in a consistent and practical manner for the complex antineoplastic treatment regimens. ${ }^{41}$

Research showed that patient adherence to long term treatment was no more than $50 \%$ but seems to be higher in case of antineoplastic treatment. Although there are multiple reasons for this, it is highly associated with the perceived fatal implications of cancer. ${ }^{42}$ This was consistent with our systematic review where patients were noted to be highly adherent to treatment. Patients noted that forgetting to take the treatment was often due to an alteration in their daily routine such as going on vacation or visiting friends. They also described of being in doubt whether they had taken the right amount of tablets or whether they had failed to take the treatment at the exact time. ${ }^{32,35}$ Patients who had received various antineoplastic treatments had a risk of developing more secondary effects which may result in lack of adherence and poor concordance to the current prescribed treatment. Therefore, the patients necessitate specific advice when changing from one medicine to another. ${ }^{32}$

This systematic review identified misconceptions that patients had about treatment especially in relation to efficacy. From a biomedical perspective, chemotherapy in oral formulation has similar efficacy as parenteral and hence is certainly not associated to treat less 'serious' cancers. Other patients believed that they were suffering from a milder cancer compared to other patients as they were receiving oral chemotherapy. ${ }^{31}$ Patients did not always understand or were provided with the rationale behind certain requirements of the treatment. For instance, breaks between treatments were either medically prescribed interruptions according to treatment protocol or due to the occurrence of adverse effects. Patients associated these breaks as periods of relief and freedom from constraints to the medicine plan such as 'holidays' or as burdensome periods with worsening of adverse effects and fear of recurrence. ${ }^{33,35}$ This emphasised the importance of involving patients in decision making about their treatment and the explanation of treatment. ${ }^{32}$

During the treatment journey patients are not only experiencing physical effects but also psychological effects with a myriad of emotions. As a result of fear of modification or discontinuation of treatment, patients delay in reporting adverse effects to healthcare professionals. ${ }^{32,35}$ However, patients who experienced minimal adverse effects thought that their treatment was not effective. This induced unnecessary concern and stress to the patients. ${ }^{28,30}$

Consistent with other studies, nausea and vomiting are the most common adverse drug reactions experienced by patients. Studies showed that patients required increased doses of anti-emetic treatment in 
order to manage these symptoms. Due to the common occurrence of adverse effects with antineoplastic medicine, it is vital that patients would be able to identify these toxicities and be advised on what measures to follow. ${ }^{29,36,41}$ Reasons provided by patients about lack of reporting of adverse effects were uncertainty about severity of adverse effects, fear of withholding treatment and waiting for the next appointment rather than contacting the healthcare professional immediately. Delayed reporting of adverse effects to healthcare professionals may lead to a detrimental effect to the patients themselves. ${ }^{32}$

Cancer treatment transformed and dominated the patient's social and family life. The patients acknowledged support from family members, peers, support groups and healthcare professionals during their treatment and also their need to develop coping skills. ${ }^{29,30,33,35,36}$ This will identify the importance of the provision of holistic care to the patients with cancer at all stages of the treatment journey, taking into consideration their physical, psychological, social and spiritual well-being. This systematic review will empower healthcare professionals to consider all the aspects of PLEM in their practice in the area of cancer treatment in order to help patients achieve a better quality of life during the treatment journey. The complexity of cancer treatment necessitates more patient involvement. Interprofessional collaboration between healthcare professionals in primary and tertiary settings together with the carer are needed to ensure services that meet the patient's needs. Educational and motivational strategies adapted and reenforced at different time-points during the treatment are necessary to address issues particularly related to aspects of burden.

Future research should focus on interventions that may be practiced by healthcare professionals to enhance patient's empowerment and encourage patients to take more active role in their cancer treatment. Studies should also be conducted on patients refusing to initiate or discontinue treatment with antineoplastic medicines to understand their beliefs, perceptions and attitudes.

\section{Limitations}

This systematic review followed a comprehensive search strategy in six databases since their respective inception. Identification of studies and data extraction was performed by 2 independent reviewers so as to reduce bias and improve the rigour. However this systematic review has its limitations. The included studies had to focus on the whole concept of PLEM, which means that all 3 themes of medicine-related burden, medicine-taking practice and medicine-related beliefs had to be discussed in the same publication. This is due to the overwhelming amount of publications focusing on one particular aspect and to offer researchers a broad complete picture of the inter-relationship between the 3 themes in a particular setting experienced by the patient. Studies that assess adherence to antineoplastic agents have been conducted but this systematic review included only those studies that also involved medicine-related beliefs and medicine-related burden. Therefore adherence to antineoplastic medicines is being discussed in relation to a holistic aspect of the patients' lived experience with medicines. This systematic review relied on secondary data and combined data from different methodologies and of different quality. Hence this resulted in the provision of limited detail to the authors and increased the element of bias in the interpretation of the results. The review only included studies published in English, which might have resulted in publication bias. In addition, grey literature including conference abstracts was not included in this review. Since the review included studies conducted in different countries and settings, patients provided their experiences based on their healthcare systems which may vary from country to country. Although all patients were suffering from solid tumours and receiving antineoplastic medicines, different cancer types may require diverse treatment regimens which vary in complexity. This may lead to increased heterogeneity of the review results. Various confounding factors such as patient characteristics, comorbidities, environmental factors and time-points in the treatment journey when the study was conducted may have affected the findings. 


\section{Conclusion}

This systematic review elicits a comprehensive assessment of the patients' needs which is crucial for patient-centred care. The adapted model of PLEM for patients with solid tumours receiving antineoplastic medicines explains the dynamic processes and socio-cultural influences that affect medicine-related beliefs, medicine-taking practice and medicine-related burden. It shows that patients undergo a continuous process of reinterpretations of the phenomenon along the treatment journey.

Patients are experts by experience as they provide a unique perspective on their disease state and required care. The understanding of the patients' experience with the antineoplastic medicines sheds light on the patients' needs and support services needed during this journey. This will ultimately lead to better health outcomes and improved quality of healthcare services.

\section{Conflict of interest: None}

Funding: This research did not receive any specific grant from funding agencies in the public, commercial, or not-for-profit sectors.

\section{References}

1. Chaddah,

Cell Network.

Cancers:

solid tumor. https://pdfs.semanticscholar.org/fe02/ee8c0df114696097eae43b2439fe2209b80c.pdf?_ga=2.40667362.1 122135331.1548737665-1120820608.1548737665; 2013 Accessed 13.12.18.
2. American
Cancer Society.
(2018)
Cancer
Facts
and Figures. https://www.cancer.org/content/dam/cancer-org/research/cancer-facts-and-statistics/annual-cancer-factsand-figures/2018/cancer-facts-and-figures-2018.pdf; 2018 Accessed 13.12.18.

3. International agency for research on cancer and World Health Organisation. Cancer today. http://gco.iarc.fr/today/data/factsheets/cancers/10_8_9-Colorectum-fact-sheet.pdf; 2018 Accessed 13.12.18.

4. Jemal A, Bray F, Center MM, Ferlay J, Ward E, Forman D. Global Cancer Statistics. Ca Cancer J Clin. 2011;61:69-90.

5. Bray F, Jemal A, Grey N, Ferlay J, Forman D. Global cancer transitions according to the Human Development Index (2008-2030): a population-based study. The Lancet Oncology. 2012;13:790-801.

6. Phillips JL, Currow DC. Cancer as a chronic disease. Collegian. 2010;17:47-50.

7. Miller KD, Siegel RL, Lin CC. et al. Cancer Treatment and Survivorship Statistics. Ca Cancer J Clin. 2016;66:271-289.

8. Longtin Y, Sax H, Leape LL, Sheridan SE, Donaldson L, Pittet D. Patient participation: current knowledge and applicability to patient safety. Mayo Clinic proceedings. 2010;85:53-62.

9. Hoos A, Anderson J, Boutin M, Dewulf L, Geissler J, Johnston G, Joos, A., Metcalf M, Regnante J, Sargeant I, Schneider RF, Todaro V, Tougas, G. (2015). Partnering With Patients in the Development and Lifecycle of Medicines: A Call for Action. Therapeutic innovation \& regulatory science. 2015;49:929-939.

10.Cipolle RJ, Strand LM, Morley PC. Pharmaceutical care practice: The clinician's guide. 2nd ed. New York: McGraw Hill; 2004.

11. Shoemaker SJ, Ramalho de Oliveira D. Understanding the meaning of medications for patients: the medication experience. Pharm World Sci. 2008;30:86-91.

12.Todres L, Holloway I. Descriptive phenomenology: Life-world as evidence. In: Rapport F, ed. New qualitative methodologies in health and social care research. London: Routledge; 2004.

13.Mapp T. Understanding phenomenology: the lived experience. British Journal of Midwifery 2008;16:308-311.

14.Mohammed MA, Moles RJ, Chen TF. Medication-related burden and patients' lived experience with medicine: a systematic review and metasynthesis of qualitative studies. BMJ Open. 2016;6:e10035. 
15.Tordoff J, Simonsen K, Thomson WM, Norris PT. "It's just routine." A qualitative study of medicinetaking amongst older people in New Zealand. Pharm World Sci. 2010;32:154-161.

16.Sav A, Kendall E, McMillan SS, Kelly F, Whitty JA., King MA, Wheeler AJ. 'You say treatment, I say hard work': treatment burden among people with chronic illness and their carers in Australia. Health and Social Care in the Community. 2013;21:665-674.

17.Koczwara B.Cancer and chronic conditions. Singapore:Springer Science and Business Media; 2016.

18. Goldkuhle M, Narayan VM, Weigl A, Dahm, P, Skoetz N. A systematic assessment of Cochrane reviews and systematic reviews published in high-impact medical journals related to cancer. $B M J$ Open. 2018;8:e20869.

19.PRISMA. PRISMA for systematic review protocols (PRISMA-P) http://www.prismastatement.org/Extensions/Protocols.aspx; 2015 Accessed 03.12.18.

20. Brincat A, Vella Bonanno P, Stewart D, Weidmann A. Patients' lived experiences of cytotoxic medications prescribed for the management of malignant solid tumours: a systematic review. http://www.crd.york.ac.uk/PROSPERO/display_record.php?ID=CRD42016048457; 2016 Accessed 23.11.18

21.Critical appraisal skills programme. CASP Checklist. http://www.casp-uk.net/casp-tools-checklists; 2017 Accessed 03.12.18.

22.Equator Centre. Equator Network: Enhancing the quality and transparency of health research. https://www.equator-network.org/;2018 Accessed 24.11.18.

23.McMaster University. Effective Public Health Practice Project. Quality Assessment Tool for quantitative studies (2012-2018). https://merst.ca/ephpp/; 2018 Accessed 23.11.18

24.Aguirre RT, Bolton KW. Qualitative interpretive meta-synthesis in social work research: Uncharted territory. Journal of Social Work. 2013;14:279-294.

25.Maxwell D, Robinson SR, Rogers K. "I keep it to myself": A qualitative meta-interpretive synthesis of experiences of postpartum depression among marginalised women. Health \& Social Care in the Community. 2018 [Epub ahead of print]

26.Nye E, Melendez $\square$ Torres GJ, Bonell C. Origins, methods and advances in qualitative meta $\square$ synthesis. Rev Educ. 2016;4:57-79.

27. Moher D, Liberati A, Tetzlaff J, Altman DG, The PRISMA Group. Preferred Reporting Items for Systematic Reviews and Meta-Analyses: The PRISMA Statement. PLoS Med. 2009;6:e1000097

28. Yokoyama dos Anjos AC, Zago MMF. The Cancer Chemotherapy experience in a patient's view. Revista Latin-Americana de Enfermagem 2005;14:1-8

29.Bergkvist K, Wengstrom Y. Symptom experiences during chemotherapy treatment-with focus on nausea and vomiting. European Journal of Oncology Nursing. 2006;10:21-29.

30.Browall M, Gaston-Johansson F, Danielson E. Postmenopausal women with breast cancer. Cancer Nursing. 2006;29:34-42.

31.Bell K. 'If it almost kills you that means it's working!' Cultural models of chemotherapy expressed in a cancer support group. Social Science \& Medicine. 2009;68:169-176.

32.Regnier Denois V, Poirson J, Nourissat A, Jacquin, JP, Guastalla, JP, Chauvin F. Adherence with oral chemotherapy: results from a qualitative study of the behaviour and representations of patients and oncologists. European Journal of Cancer Care. 2011;20:520-527.

33. Gerber DE, Hamann HA, Rasco DW, Woodruff S, Craddock Lee J. Patient Comprehension and attitudes toward maintenance chemotherapy for lung cancer. Patient Education and Counseling. 2012;89:102-108.

34.Timmers L, Boons CCLM., Moes-ten Hove J, Smit EF, van de Ven PM, Aerts JG, Swart EL, Boven E, Hugtenburg JG. Adherence, exposure and patients' experiences with the use of erlotinib in non-small cell lung cancer. Journal of Cancer Research and Clinical Oncology. 2015;141:1481-1491.

35. Gassmann C, Kolbe N, Brenner A. Experiences and coping strategies of oncology patients undergoing oral chemotherapy: first steps of a grounded theory study. European Journal of Oncology Nursing. 2016;23:106-114. 
36. Komatsu H, Yagasaki K, Yamauchi H, Yamauchi,T. Patients' perspectives on creating a personal safety net during chemotherapy. Clinical Journal of Oncology Nursing. 2016;20:13-16.

37.Timmers L, Boons CCLM, Mangnus D, van de Ven PM, Van den Berg PH, Aart B, Swart EL, Honeywell RJ, Peters GJ, Boven E, Hugtenburg, JG. Adherence and patients' experiences with the use of capecitabine in daily practice. Frontiers in Pharmacology. 2016;7:1-10.

38.Pomey MP, Ghadiri DP, Karazivan P, Fernandez N, Clavel N. Patients as Partners: A Qualitative Study of Patients' Engagement in Their Health Care. PLoS ONE. 2015;10:e0122499.

39.Vahdat S, Hamzehgardeshi L, Hessam S, Hamzehgardeshi, Z. Patient Involvement in Health Care Decision Making: A Review. Iranian Red Crescent Medical Journal. 2014;16:e12454.

40.Tadic D, Bozovic Spasojevic I, Tomasevic ZI, Dejanovic SD. Oral administration of antineoplastic agents: the challenges for healthcare professionals. JBUON 2015; 20:690-698.

41.Chopra D, Rehan HS, Sharma V, Ritu Mishra R. Chemotherapy-induced adverse drug reactions in oncology patients: A prospective observational survey. Indian J Med Paediatr Oncol. 2016;37:42-46.

42.Barillet M, Prevost V, Joly F, Clarisse B. Oral antineoplastic agents: how do we care about adherence? Br J Clin Pharmacol. 2015;80:1289-1302. 
Table 1 Information about the studies included in the systematic review arranged in chronological order

\begin{tabular}{|c|c|c|c|c|c|c|}
\hline $\begin{array}{l}\text { Study } \\
\text { [Authors, } \\
\text { year, } \\
\text { country] }\end{array}$ & $\begin{array}{l}\text { Stated aim(s) and } \\
\text { objective(s) }\end{array}$ & $\begin{array}{c}\text { Setting and } \\
\text { number of } \\
\text { respondents }\end{array}$ & Study design & $\begin{array}{l}\text { Method of data } \\
\text { collection }\end{array}$ & Data analysis & Key findings \\
\hline $\begin{array}{l}\text { Yokoyama } \\
\text { dos Anjos } \\
\text { and Zago, } \\
\text { 2005, Brazil }\end{array}$ & $\begin{array}{l}\text { To understand the meaning } \\
\text { of the chemotherapy from } \\
\text { the patient's point of view }\end{array}$ & $\begin{array}{l}\text { Oncology } \\
\text { hospital and } \\
\text { patient's home, } \\
n=1\end{array}$ & $\begin{array}{c}\text { Qualitative } \\
\text { ethnographic case } \\
\text { study }\end{array}$ & $\begin{array}{l}\text { - Semi-structured } \\
\text { interviews } \\
\text { - non-structured } \\
\text { observations } \\
\text { - patient's field diary }\end{array}$ & $\begin{array}{l}\text { Interpretative } \\
\text { anthropology }\end{array}$ & $\begin{array}{l}\text { Seven unities of meaning were identified: } \\
\text { 1. discovery of cancer and search for assistance, } \\
\text { 2. knowledge about cancer, } \\
\text { 3. trajectory of chemotherapy, } \\
\text { 4. networks of support, } \\
\text { 5. lack of control of one's life, } \\
\text { 6. uncertainty about the future, } \\
\text { 7. expectation in the future. } \\
\text { The patient's view on her experience with cancer } \\
\text { chemotherapy as "the loss of the control over one's } \\
\text { life" were summarised. The study emphasised the need } \\
\text { for nurse care to follow up the patient throughout the } \\
\text { whole process and offer resources to the patient to } \\
\text { resume control of her life during this critical period. }\end{array}$ \\
\hline $\begin{array}{l}\text { Bergkvist } \\
\text { and } \\
\text { Wengstrom, } \\
2006 \text {, } \\
\text { Sweden }\end{array}$ & $\begin{array}{l}\text { To acquire a deeper } \\
\text { understanding of cancer } \\
\text { patients' symptom } \\
\text { experiences with focus on } \\
\text { nausea and vomiting } \\
\text { during chemotherapy } \\
\text { treatment and the } \\
\text { consequences these have } \\
\text { on daily life }\end{array}$ & $\begin{array}{c}\text { Oncology } \\
\text { hospital, } n=9\end{array}$ & Qualitative study & $\begin{array}{l}\text { Semi-structured } \\
\text { interviews }\end{array}$ & Content analysis & $\begin{array}{l}\text { Five main categories in the experience of } \\
\text { chemotherapy treatment were identified: } \\
\text { 1. before cancer diagnosis, } \\
\text { 2. being ill-consequences on daily life, } \\
\text { 3. going through chemotherapy treatment, } \\
\text { 4. coping with treatment, } \\
\text { 5. after treatment-looking forward to a normal life. } \\
\text { The study describes that the experience of receiving } \\
\text { chemotherapy is a process that evolves over time. The } \\
\text { findings suggest that experiences of nausea and } \\
\text { vomiting during chemotherapy treatment have a } \\
\text { profound effect on the cancer experience and thus may } \\
\text { influence future decisions relating to new treatment. }\end{array}$ \\
\hline $\begin{array}{l}\text { Browall, } \\
\text { Gaston- }\end{array}$ & $\begin{array}{l}\text { To describe the experience } \\
\text { of postmenopausal women }\end{array}$ & $\begin{array}{c}\text { Oncology } \\
\text { hospital and }\end{array}$ & Qualitative study & interviews & Content analysis & Four themes were identified: \\
\hline
\end{tabular}




\begin{tabular}{|c|c|c|c|c|c|c|}
\hline $\begin{array}{l}\text { Johansson } \\
\text { and } \\
\text { Danielson, } \\
2006, \\
\text { Sweden }\end{array}$ & $\begin{array}{l}\text { with breast cancer who } \\
\text { undergo } \\
\text { chemotherapy treatment }\end{array}$ & $\begin{array}{l}\text { patient's home, } \\
n=20\end{array}$ & & with one open question & & $\begin{array}{l}\text { 1. the fear of the unknown, } \\
\text { 2. affects on body and mind, } \\
\text { 3. to get by, } \\
\text { 4. a transformed life. } \\
\text { The participants described feelings of imbalance in } \\
\text { their relationships due to lack of support from those } \\
\text { close to them. The support from healthcare } \\
\text { professionals was experienced both positively and } \\
\text { negatively; with most of the participants revealing } \\
\text { variations in the healthcare professionals attitude, } \\
\text { knowledge, and empathy. Women who decided not to } \\
\text { work during the treatment felt pressure from society } \\
\text { and healthcare professionals to get back to work as } \\
\text { soon as possible. The participants expressed a feeling } \\
\text { of not being afraid of dying but wanted more time to } \\
\text { prepare themselves. }\end{array}$ \\
\hline $\begin{array}{l}\text { Bell, 2009, } \\
\text { Canada }\end{array}$ & $\begin{array}{l}\text { To explore patients' } \\
\text { perceptions of adjuvant } \\
\text { chemotherapy }\end{array}$ & $\begin{array}{l}\text { Cancer support } \\
\text { group, } \mathrm{n}=8\end{array}$ & Ethnography & $\begin{array}{l}\text { - Semi-structured } \\
\text { interviews } \\
\text { - participant } \\
\text { observation at the } \\
\text { support group } \\
\text { meetings }\end{array}$ & $\begin{array}{l}\text { Thematic } \\
\text { analysis }\end{array}$ & $\begin{array}{l}\text { Three themes were identified: } \\
\text { 1. Hurting the good cells \& really hurting cancer cells, } \\
\text { 2. Getting a "full dose", } \\
\text { 3. Oral vs intravenous chemotherapy. } \\
\text { A cultural model of chemotherapy was noted which } \\
\text { stressed the value of suffering and pain as means of } \\
\text { monitoring treatment effectiveness and even the } \\
\text { possibility of cure. This framework differs from } \\
\text { biomedical understanding of treatment in various } \\
\text { aspects, with implications on anxiety levels } \\
\text { experienced by the patients and the risk of recurrence. }\end{array}$ \\
\hline $\begin{array}{l}\text { Regnier } \\
\text { Denois, } \\
\text { Poirson, } \\
\text { Nourissat, } \\
\text { Jacquin, } \\
\text { Guastalla } \\
\text { and } \\
\text { Chauvin, } \\
\text { 2011, France }\end{array}$ & $\begin{array}{l}\text { To describe and } \\
\text { understand existing } \\
\text { practice for capecitabine } \\
\text { and to evaluate the } \\
\text { perceptions and } \\
\text { descriptions of patients and } \\
\text { oncologist about the } \\
\text { prescription of } \\
\text { capecitabine }\end{array}$ & $\begin{array}{l}2 \text { oncology } \\
\text { hospitals, } n=45\end{array}$ & Qualitative study & 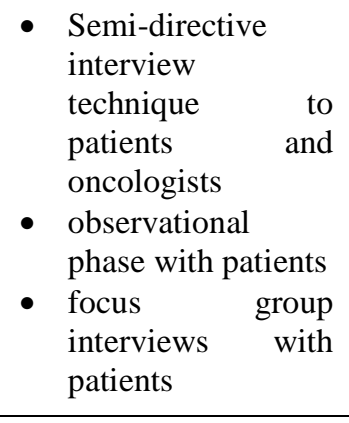 & Content analysis & $\begin{array}{l}\text { Adherence, which in this study was defined as being } \\
\text { against not taking their treatment, generally seemed } \\
\text { satisfactory. Results showed a wide diversity in the } \\
\text { prescribers' practices, who often made decisions based } \\
\text { on their experience of practice guidelines for } \\
\text { intravenous chemotherapies. Although the results for } \\
\text { the patients do not suggest deliberate non-adherence, } \\
\text { they show poor observance of the dose schedule. The } \\
\text { study identified the patient's inability to recognise and } \\
\text { report important signs of harmful toxicity. }\end{array}$ \\
\hline
\end{tabular}




\begin{tabular}{|c|c|c|c|c|c|c|}
\hline $\begin{array}{l}\text { Gerber, } \\
\text { Hamann, } \\
\text { Rasco, } \\
\text { Woodruff } \\
\text { and } \\
\text { Craddock } \\
\text { Lee, 2012, } \\
\text { United } \\
\text { States } \\
\end{array}$ & $\begin{array}{l}\text { To gain insight into patient } \\
\text { perceptions of } \\
\text { maintenance chemotherapy } \\
\text { for advanced } \\
\text { non-small cell lung cancer }\end{array}$ & $\begin{array}{l}\text { Hospital } \\
\text { (inpatient), } \mathrm{n}=47\end{array}$ & Qualitative study & Focus group & $\begin{array}{c}\text { Thematic content } \\
\text { analysis }\end{array}$ & $\begin{array}{l}\text { Five themes were identified: } \\
\text { 1. survival benefits, disease control, and "buying } \\
\text { time", } \\
\text { 2. the importance of "doing something", } \\
\text { 3. quality of life concerns, } \\
\text { 4. the role of provider opinion/preference, } \\
\text { 5. the importance of logistics. }\end{array}$ \\
\hline $\begin{array}{l}\text { Timmers, } \\
\text { Boons, } \\
\text { Moes-ten } \\
\text { Hove, Smit, } \\
\text { van de Ven, } \\
\text { Aerts, Swart, } \\
\text { Boven and } \\
\text { Hugtenburg, } \\
2015 \text {, } \\
\text { Netherlands }\end{array}$ & $\begin{array}{l}\text { To assess adherence to } \\
\text { erlotinib treatment and } \\
\text { evaluate experiences of } \\
\text { patients as well as the } \\
\text { relationship between } \\
\text { medicine adherence, } \\
\text { erlotinib exposure and } \\
\text { symptoms }\end{array}$ & 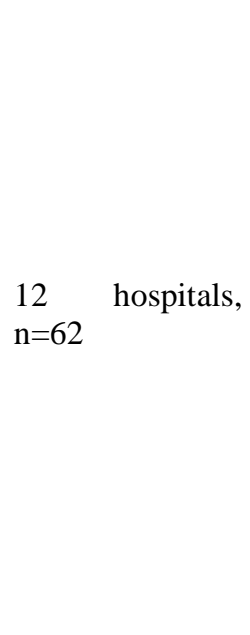 & $\begin{array}{c}\text { Prospective } \\
\text { observational cohort } \\
\text { study }\end{array}$ & $\begin{array}{l}\text { - Patients reported } \\
\text { questionnaires } \\
\text { - patients' medical file } \\
\text { - adherence measured } \\
\text { with medication } \\
\text { event monitoring } \\
\text { system (MEMS) } \\
\text { - blood samples }\end{array}$ & $\begin{array}{l}\text { Mann-Whitney } \\
\text { test, } \\
\text { Fisher exact test }\end{array}$ & $\begin{array}{l}\text { According to the Belief about Medicines Questionnaire } \\
(\mathrm{BMQ}), 40 \%(\mathrm{n}=25) \text { of patients were classified as } \\
\text { "accepting" treatment with erlotinib. 55\% ( } \mathrm{n}=34) \text { of } \\
\text { patients who had started their treatment with erlotinib, } \\
\text { considered their treatment to be of high necessity and } \\
\text { high concern. MEMS data of } 55 \text { patients revealed a } \\
\text { mean adherence of } 96.8 \pm 4.0 \% \text {. Over one-third of } \\
\text { patients had an adherence rate }<95 \% \text {. At } 1 \text { month, } 21 \\
\% \text { of patients did not always correctly take erlotinib } \\
\text { without food. Associated risk factors were older age, } \\
\text { suboptimal adherence, ocular symptoms and stomatitis } \\
\text { (all p < } 0.05) \text {. After } 1 \text { month of treatment, fatigue } \\
\text { (91\%) and rash ( } 86 \%) \text { were the most common } \\
\text { symptoms reported. AUCss of erlotinib was higher in } \\
\text { patients with rash and patients with moderate-severe } \\
\text { anorexia (both p < } 0.05) \text {. }\end{array}$ \\
\hline $\begin{array}{l}\text { Gassmann, } \\
\text { Kolbe and } \\
\text { Brenner, } \\
2016, \\
\text { Switzerland }\end{array}$ & $\begin{array}{l}\text { To explore the experiences } \\
\text { of patients undergoing oral } \\
\text { chemotherapy and } \\
\text { investigate the impact of } \\
\text { oral chemotherapy on their } \\
\text { daily life }\end{array}$ & $\begin{array}{l}\text { Outpatients } \\
\text { clinic of an } \\
\text { urban hospital, } \\
n=6\end{array}$ & Grounded theory & Open interviews & \begin{tabular}{|} 
Constant \\
comparison \\
coding and \\
categorising in \\
line with \\
paradigm model
\end{tabular} & $\begin{array}{l}\text { Participants reported physical and emotional reluctance } \\
\text { towards oral chemotherapy as well as toxic side effects. } \\
\text { Feeling responsible emerged as a core phenomenon } \\
\text { with influences from context and intervening } \\
\text { conditions. All participants intended to adhere to } \\
\text { treatment despite being a challenging task due to } \\
\text { complex treatment regimen. Belief in the effectiveness } \\
\text { of the therapy was a strengthening factor. Participants } \\
\text { struggled between the necessity of adhering to oral } \\
\text { chemotherapy and the practicality as well as emotional } \\
\text { difficulties of daily life. Hence, patients developed } \\
\text { coping strategies during the treatment journey. In } \\
\text { consequence, oral chemotherapy was found to be }\end{array}$ \\
\hline
\end{tabular}




\begin{tabular}{|c|c|c|c|c|c|c|}
\hline & & & & & & $\begin{array}{l}\text { omnipresent by determining the participants' thoughts } \\
\text { and daily life. }\end{array}$ \\
\hline $\begin{array}{l}\text { Komatsu, } \\
\text { Yagasaki, } \\
\text { Yamauchi } \\
\text { and } \\
\text { Yamauchi, } \\
\text { 2016, Japan }\end{array}$ & $\begin{array}{l}\text { To explore the experiences } \\
\text { of patients with breast } \\
\text { cancer who had received } \\
\text { chemotherapy to } \\
\text { understand how they } \\
\text { perceived the impact of the } \\
\text { treatment on their daily } \\
\text { lives }\end{array}$ & $\begin{array}{l}\text { Outpatients of } \\
\text { breast or } \\
\text { oncology centre } \\
\text { clinic in a } \\
\text { hospital, } n=17\end{array}$ & Grounded theory & $\begin{array}{l}\text { Semi-structured } \\
\text { interviews }\end{array}$ & $\begin{array}{c}\text { Analysis of } \\
\text { transcripts by } \\
\text { first coding and } \\
\text { then labelling the } \\
\text { meanings. } \\
\text { Subcategories } \\
\text { were identified } \\
\text { to lead } \\
\text { categories. Core } \\
\text { categories } \\
\text { emerged by } \\
\text { connecting } \\
\text { categories and } \\
\text { subcategories. }\end{array}$ & $\begin{array}{l}\text { Patients created personal safety nets for physical, } \\
\text { emotional and social contexts during chemotherapy, } \\
\text { even though they found everyday life to be more } \\
\text { challenging because of the disease and side effects. } \\
\text { Through their safety nets, the participants felt more } \\
\text { confident and in control of their lives and were willing } \\
\text { to take a positive approach towards making their lives } \\
\text { meaningful. In anticipation of side effects of } \\
\text { chemotherapy, participants "hibernated" and consumed } \\
\text { minimal amount of energy. They also created a } \\
\text { protective inner space in which they were able to } \\
\text { tolerate fear and anxiety and exert self-control. In } \\
\text { maintaining their daily routines, patients felt more } \\
\text { confident to balance their lives and illness and helped } \\
\text { them to tolerate uncertainty. }\end{array}$ \\
\hline $\begin{array}{l}\text { Timmers, } \\
\text { Boons, } \\
\text { Mangnus, } \\
\text { van de Ven, } \\
\text { Van den } \\
\text { Berg, Aart } \\
\text { B, Swart, } \\
\text { Honeywell, } \\
\text { Peters, } \\
\text { Boven, } \\
\text { Hugtenburg, } \\
\text { 2016, } \\
\text { Netherlands }\end{array}$ & $\begin{array}{l}\text { To get insight into } \\
\text { patients' experiences with } \\
\text { the use of capecitabine in } \\
\text { daily practice and the } \\
\text { various aspects that govern } \\
\text { adherence }\end{array}$ & $\begin{array}{l}10 \text { hospitals, } \\
\mathrm{n}=92\end{array}$ & $\begin{array}{c}\text { Prospective } \\
\text { observational cohort } \\
\text { study }\end{array}$ & $\begin{array}{l}\text { - Adherence assessed } \\
\text { using a pill count, } \\
\text { pharmacy data and } \\
\text { dosing information } \\
\text { obtained from the } \\
\text { patients' medical file } \\
\text { (PPP method) } \\
\text { - self-reported } \\
\text { adherence measured } \\
\text { using the Medication } \\
\text { Adherence Report } \\
\text { Scale. p patients reported } \\
\text { questionnaires } \\
\text { - blood samples }\end{array}$ & $\begin{array}{l}\mathrm{X}^{2} \text {-test, } \\
\text { Fisher's exact } \\
\text { test, } \\
\text { Logistic } \\
\text { regression }\end{array}$ & $\begin{array}{l}\text { Most patients }(91 \%) \text { had an adherence rate of } \geq 95 \text { and } \\
\leq 105 \% \text {. Symptoms were frequently reported and the } \\
\text { dosing regimen was adjusted by the physician at least } \\
\text { once in } 62 \% \text { of patients }(\mathrm{n}=57) \text {. According to BMQ, } \\
50 \% \text { ( } \mathrm{n}=46 \text { ) of patients were classified as "accepting" } \\
\text { capecitabine. These patients were associating their } \\
\text { medicine with a high necessity and low concern prior } \\
\text { to initiation of treatment. } 44 \% \text { ( }=40 \text { ) patients who had } \\
\text { started their treatment with capecitabine considered } \\
\text { their treatment to be of high necessity and high } \\
\text { concern. According to the Brief Illness Perception } \\
\text { Questionnaire (IPQ), patients were found to believe } \\
\text { that treatment with capecitabine will help their illness } \\
\text { and achieve treatment control. This is evidenced by the } \\
\text { mean value which improved from baseline }(7.8 \pm 1.8) \text { to } \\
\text { cycle } 5(8.0 \pm 1.6) \text {. }\end{array}$ \\
\hline
\end{tabular}




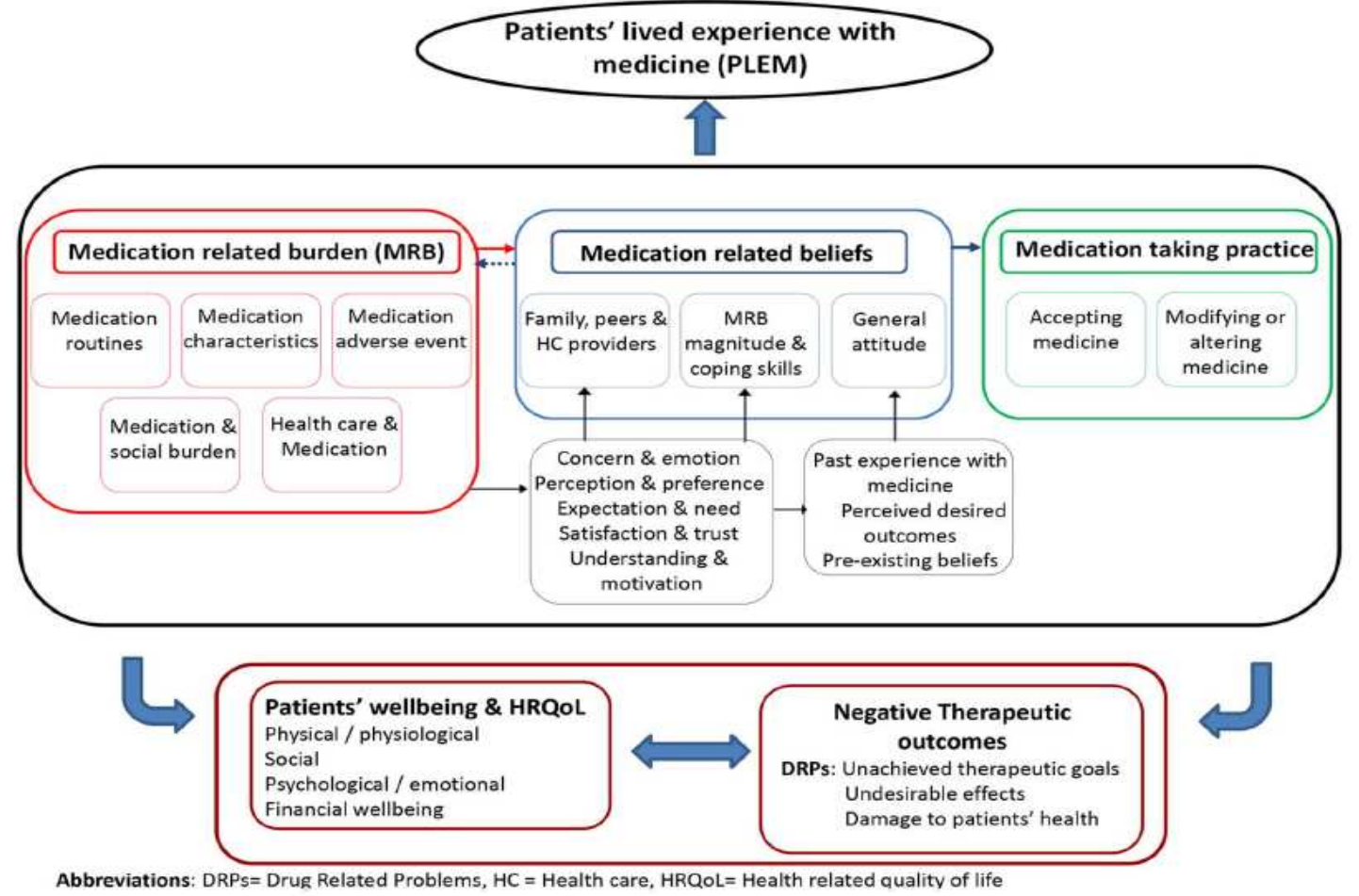

Figure 1 Conceptual model of the patients' lived experience with medicine (PLEM) as developed by Mohammed et al. (2016). The model shows the complexity of PLEM and an inter-relationship between medicine related burden, medicine related beliefs, medicine taking practice.

Adopted from: Mohammed MA, Moles RJ, Chen TF. Medication-related burden and patients' lived experience with medicine: a systematic review and metasynthesis of qualitative studies. BMJ Open. 2016;6:e010035. 


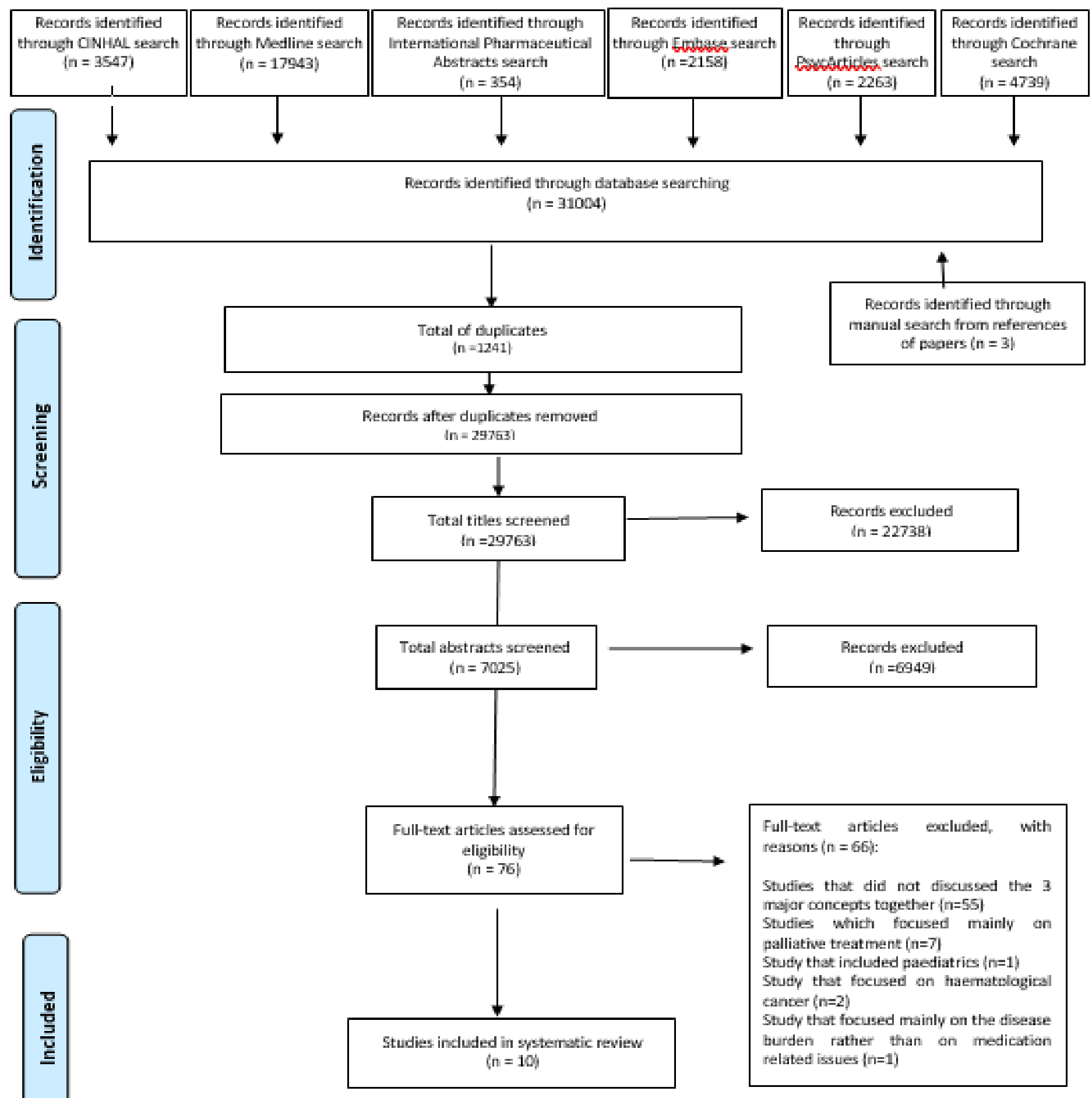

Figure 2 Prisma flow diagram showing the inclusion and exclusion of studies identified for the systematic review. Reasons for the studies being excluded are also provided. Adapted from Prisma 2009 flow diagram. ${ }^{27}$ 


\section{Patients' lived experience with medicine (PLEM)}

Medicine-related beliefs

\begin{tabular}{c}
$\begin{array}{c}\text { Family members, } \\
\text { healthcare } \\
\text { protessionals, } \\
\text { media and } \\
\text { culture influence }\end{array}$ \\
$\begin{array}{c}\text { General } \\
\text { attitude } \\
\text { towares } \\
\text { medicine }\end{array}$ \\
\hline
\end{tabular}
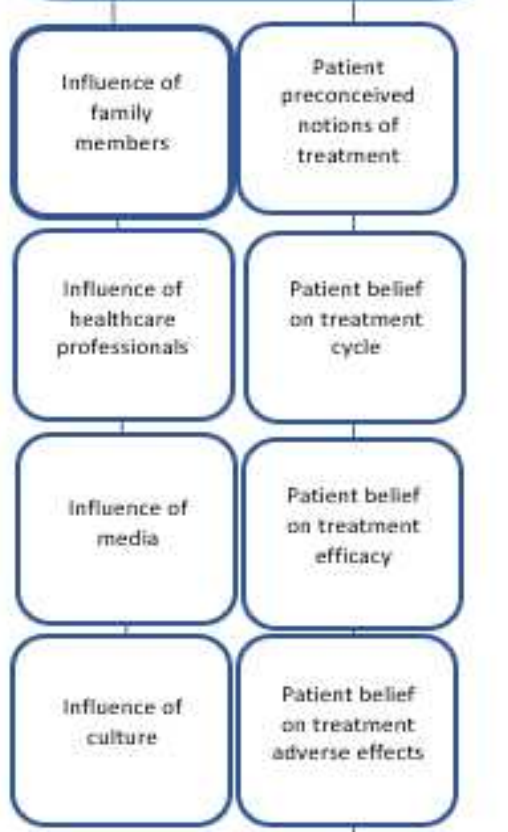

Patient belief

regarding post-

treatment
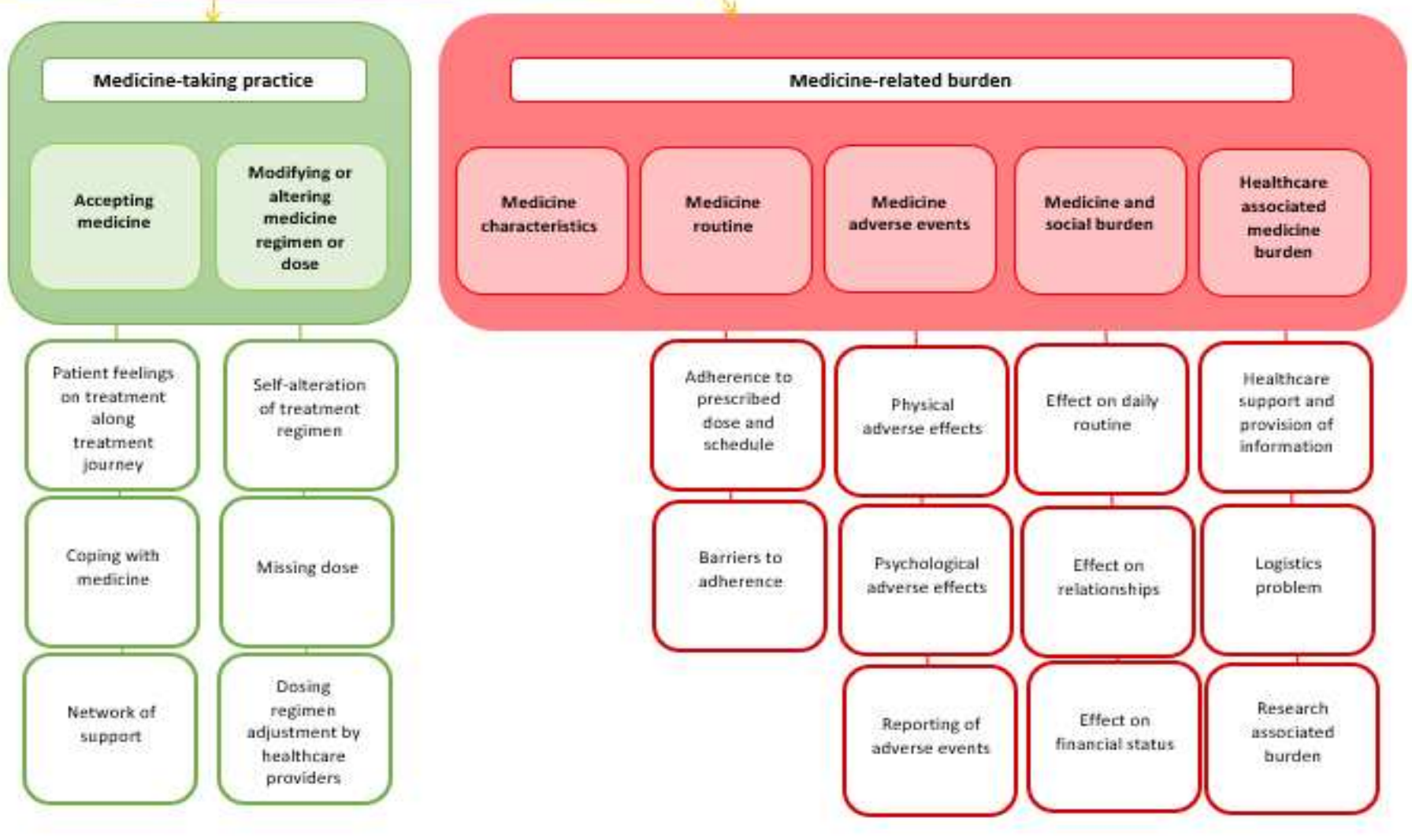

Figure 3 An adapted model of PLEM for patients with solid tumours receiving antineoplastic medicines 